Theo Tổng giám đốc WHO, Ông Tedros Adhanom Ghebreyesus cho rằng " Đại dịch này là một cuộc khủng hoảng y tế một trăm năm nay mới xảy ra một lần, những tác động của nó sẽ còn kéo dài nhiều thập kỷ nữa". Chính vì vậy, trên thế giới, sau "cú sốc choáng váng ban đầu, các nước đã áp dụng một loạn giải pháp " phi y tế " để ngăn chặn sự lầy lan của đại dịch giữa các nước, giữa các vùng, khu vực, đơn vị, gia đình, người với người. Những thay đổi này rất cần thiết để ứng phó với đại dịch COVID-19 nhưng đe dọa đến khả năng tài chính của các Bệnh viện, đặc biệt là những Bệnh viện đang gặp khó khăn trong vấn đề tài chính và những Bệnh viện phụ thuộc nhiều vào hoạt động khám chữa bệnh ngoại trú [7]

\section{KẾT LUẬN VÀ KHUYẾN NGH!}

Cần sớm sửa đổi, bổ sung các văn bản hướng dẫn về thực hiện tự chủ, tự chịu trách nhiệm của đơn vị sự nghiệp y tế công lập theo hướng tạo điều kiện thuận lợi cho các đớn vị cấp dưới, cụ thể là có hướng dẫn phù hợp với việc trích lập và sử dụng quỹ cải cách tiền lương. Kiện toàn quy trình, thủ tục giám định, thanh quyết toán BHYT cho các cơ sở y tế công lập. Định mức biên chế trong giai đoạn thực hiện lộ trình tự chủ.

\section{TÀI LIẸU THAM KHẢO}

1. Chính phủ (2006), Nghi định số $43 / 2006 / N D-C P$, ngày 25/4/2006 của Chính phủ quy định quyền tứ chủ, tự chịu trách nhiệm và thực hiện nhiệm vụ, tổ chức bộ máy, biên chế và tài chính đối với đớn vị sự nghiệp công lập, chủ biên.

2. Chính phủ (2015), Nghị định số 16/2015/ND-CP của Chính phủ : Quy định cơ chế tự chủ của đơn vị nghiệp công lập,

3. Vư hợp tác quốc tế, Bộ Y tế (2017). Chiến lược Tài chính Y tế Việt Nam giai đoạn 20162025.http://icdmoh.gov.vn/tin-tuc/chien-luoc-taichinh-y-te-viet-nam-giai-doan-20162025.html.

4. Bộ Y tế, World Health Organization (2010), Tài khoản y tế quốc gia thực hiện ở Việt Nam thới kỳ 1998-2008, Nhà Xuất bản Y học, Hà Nội.

5. Trịnh Đăng Anh (2019), Thực hiện thu chi tài chính và một số thuâan lợi khó khăn tại Bệnh viện Y học cổ truyền tỉnh Đ̇ắk Lắk giai đoạn 2016-2018, Luận văn CKII - Tổ chức quản lý y tế. Trường Đại học Y tế công cộng, Hà Nội.

6. Ninh Tiên Hoàng (2013), Thực trang hoạt động tài chính tại bênh viện đa khoa huyện Cư Kuin và Krông Ana thuộc tỉnh ĐắkLắk giai đoạn 2010-1012, Luận văn Thạc sỹ Quản lý bệnh viện. Trường Đại học Y tế Công cộng, Hà Nội.

7. Webb, E., Hernandez-Quevedo, C., Scarpetti, G., et al. (2020). Restarting more routine hospital activities during COVID-19: approaches from six countries. Eurohealth, 26(2), 68-73.

\title{
KẾT QUẢ ĐIỀU TRI VIÊM PHỔI VÀ NHIỄM KHUẨN HUYẾT DO KLEBSIELLA PNEUMONIAE SỬ DUUNG AMIKACIN CÓ GIÁM SÁT NỒNG Độ TRONG MÁU
}

\section{TÓM TẮT}

Mục tiêu: Đánh giá kết quả điều tri viêm phổi và nhiễm khuẩn huyết do Klebsiella.pneumoniae sử dụng amikacin có giám sát nồng độ trong máu và mô tả độc tính trên thận. Đối tượng và phương pháp nghiên cứư: Nghiên cứu lâm sàng can thiệp trên bệnh nhân nhiễm khuẩn huyết hoăc viêm phổi do K.pneumoniae tại khoa Hồi sức tích cực. Liều amikacin là $30 \mathrm{mg} / \mathrm{kg}$ cần nặng hiệu chỉnh (ABW). Mục tiêu giám sát nông độ thuốc trong máu (TDM) là $\mathrm{C}_{\text {peak }}$ : $45-60 \mathrm{mg} / \mathrm{L}$, $C_{\text {peak }} / \mathrm{MIC}: 8-10, \mathrm{C}_{\text {trough }}<2 \mathrm{mg} / \mathrm{L}$. Chúng tôi ghi nhân đáp ứng lâm sàng và sự phát triển tổn thương thận cấp. Kết quả: 42 bênh nhân được nhận vào nghiền cứu, có tuổi trung bình $56,1 \pm 19$. Nam giới chiếm $76,2 \%$. Điểm APACHE II 16, điểm SOFA ngày vào

* Trường Đại học y Hà Nội

Chịu trách nhiệm chính: Phạm Thị Hồng Phương

Email: hongphuong98147@gmail.com

Ngày nhận bài: 9.9.2021

Ngày phản biên khoa hoc: 2.11.2021

Ngày duyệt bài: 10.11.2021

\section{Phạm Thị Hồng Phương*, Đặng Quốc Tuấn*}

khoa 8[4,5], điểm Chalson 1[2]. Tỉ lệ sốc nhiễm khuẩn tai thời điểm dùng amikacin $35,7 \%$. Bênh nhân thơ máy chiếm $85,7 \%$. Viêm phổi chiếm $83,3 \%$. MIC của K.pneumoniae với amikacin $4[2-5]$, tî lệ $\mathrm{MIC} \leq 8$ là $92,9 \%$. Tỉ lệ bệnh nhân đáp ứng lâm sàng hoàn toàn là $57,1 \%$. Tỉ lệ đáp ứng lâm sàng hoàn toàn ngày thứ 5 tăng hơn ngày thứ 3 , ngày thứ 7 tăng hơn ngày thứ $5(p<0,05)$. Nhóm đáp ứng lâm sàng hoàn toàn và nhóm không đáp ứng lâm sàng hoàn toàn có sự khác biêt về điểm APACHE II, điểm SOFA ngày vào khoa, điểm SOFA lúc bắt đầu điều trị, Hct lúc bắt đầu điều trị và tỉ lệ thở máy $(p<0,05)$, không có sự khác biệt về $\mathrm{C}_{\text {peak }} / \mathrm{MIC}$ và MIC ( $\left.\mathrm{p}>0,05\right)$. Trong những bệnh nhân $\mathrm{C}_{\text {trough }}<2 \mathrm{mg} / \mathrm{L}$ tỉ lệ xuất hiện tổn thương thận là 38,1\% và $87,5 \%$ ơ giai đoạn nguy cơ. Thời gian xuất hiện tổn

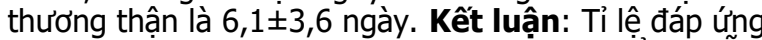
lâm sàng hoàn toàn khi điều tri viêm phổi, nhiễm khuẩn huyết do K.pneumoniae sử dụng amikacin liều $30 \mathrm{mg} / \mathrm{kg}$ ABW là 57,1\%. Bệnh nhân có điểm APACHE II cao, SOFA lúc vào khoa cao, SOFA lúc bắt đầu điều trị cao và bệnh nhân thở máy có đáp ứng lâm sàng kém hơn. Tỉ lệ tổn thương thận cấp ở các bệnh nhân nghiên cứu là $38,1 \%$. 
Tư khóa: Klebsiella pneumoniae, amikacin, giám sát nồng độ thuốc

\begin{abstract}
SUMMARY
RESULTS OF TREATMENT PNEUMONIA AND BLOODSTRE INFECTION DUE TO KLEBSTELLA PNEUMONIAE USING AMIKACIN WITH THERAPEUTIC DRUG MONITORING

Objective: Evaluate the results of treatment pneumonia and bloodstream infections due to Klebsiella pneumoniae using amikacin with therapeutic drug monitoring and describe nephrotoxicity. Subjects and methods: An interventional clinical study on patients with pneumonia and bloodstream infections due to K.pneumoniae in the ICU. The dose of amikacin was $30 \mathrm{mg} / \mathrm{kg}$ adjusted body weight (ABW). The goal of therapeutic drug monitoring (TDM) are $C_{\text {peak }}$ of $45-60 \mathrm{mg} / \mathrm{L}$, ratio $C_{\text {peak }} / \mathrm{MIC} 8-10, \mathrm{C}_{\text {trough }}$ $<2 \mathrm{mg} / \mathrm{L}$. We recorded the clinical response and development of acute kidney injury (AKI). Results: 42 patients were admitted to the study. The mean age of patients was $56.1 \pm 19$ years. Male $76.2 \%$. APACHE II score on admission ICU was 16, SOFA score on admission ICU was $8[4,5]$, Chalson score was 1[2]. The rate of septic shock at the time of amikacin administration was $35.7 \%$. Ventilator patients $85.7 \%$. Pneumonia infection $83.3 \%$. MIC of K.pneumoniae with amikacin was $4[2-5]$, MIC $\leq 8$ rate was $92.9 \%$. The overall clinical complete response rate of the treatment course was $57.1 \%$. The rate of clinical complete response on day 5 more than day 3 , day 7 more than day $5(p<0.05)$. The clinical complete response group and the non-clinical complete response group had differences on APACHE II score, SOFA score on admission, SOFA score at the beginning of treatment, Hct at the beginning of treatment and rate of mechanical ventilation $(p<0.05)$ and no differences in $\mathrm{C}_{\text {peak }} / \mathrm{MIC}$, MIC $(p>0.05)$. In patients with $C_{\text {trough }}<2 \mathrm{mg} / \mathrm{L}$, the rate of occurrence of AKI percentage was $38.1 \%$, at risk stage $(87.5 \%)$ and time of appearance $6.1 \pm 3.6$ days. Conclusions: The rate of complete clinical response when treating pneumonia and bacteremia infections due to K.pneumoniae using amikacin dose of $30 \mathrm{mg} / \mathrm{kg} \mathrm{ABW}$ was $57.1 \%$. Patients with high APACHE II score, high SOFA score on admission, high SOFA score at the beginning of treatment, requiring mechanical ventilation have a poorer clinical response. The rate of acute kidney injury was $38.1 \%$.
\end{abstract}

Keywords: Klebsiella pneumoniae, amikacin, therapeutic drug monitoring

\section{I. ĐĂT VẤN ĐỀ}

Năm 2018, tại khoa Hồi sức tích cực (HSTC) Bệnh viên Bach Mai nhiễm khuấn do $K$. pneumoniae chủ yếu là viêm phổi $(65,7 \%)$, nhiễm khuẩn huyết chiếm $(21,9 \%)^{2}$. K.pneumoniae xu hướng kháng hâu hết các kháng sinh. Amikacin vẫn giữ được mức độ nhạy cảm tương đối cao $(64,7 \%)($ năm 2018)² .

Amikacin diệt khuẩn phụ thuộc nồng độ, biến thiên lớn dược động học, khoảng điều trị hẹp, việc giám sát nồng độ thuốc trong máu (TDM) để tối ưu điều trị và giảm độc tính.

Năm 2016 Bồ Y Tế đưa ra quyết định 772 hướng dẫn quản lý sử dụng kháng sinh trong bệnh viện. Năm 2019, giám đốc Bệnh Viện Bạch Mai phê duyệt quy trình TDM và hiệu chỉnh liều dùng Amikacin trên bênh nhân người lớn. Do vậy, chúng tôi tiến hành nghiên cứu đánh giá kết quả điều trị viêm phổi và nhiễm khuẩn huyết do Klebsiella.pneumoniae sử dụng Amikacin có giám sát nồng độ trong máu và mô tả độc tính trên thận tại khoa HSTC Bệnh viện Bạch Mai

\section{II. ĐỐI TƯỢNG VÀ PHƯƠNG PHÁP NGHIÊN CỨU \\ 2.1. Đối tượng nghiên cứu}

Tiêu chuấn chọn. BN nhiễm khuẩn huyết (NKH) hoặc Viêm phổi (VP) do K.pneumoniae (chuẩn đoán xác định theo tiêu chuẩn $\mathrm{CDC}$ 2014); K.pneumoniae nhạy cảm với Amikacin (theo CLSI); Không có tiền sử dị ứng với Amikacin; Trên 18 tuổi

Tiêu chuấn loại trừ

- Dùng Amikacin không đủ 72h; Sử dụng đồng thời amikacin đường khác (khí dung); Không tuân thủ theo quy trình định lượng nồng độ thuốc trong máu

- Tiêu chuẩn loai trừ mô tả đôc tính trên thận: Bệnh nhân suy thận cấp trước khi điều trị Amikacin, suy thận mạn giai đoạn cuối phải lọc máu chu kì hoăc chưa phải lọc máu chu kì nhưng không biết creatinine nền, CRRT ngay trước khi sử dung Amikacin

\subsection{Phương pháp nghiên cứu}

2.2.1. Thiêt kế nghiên cứu và quy trinh nghiên cứu

- Nghiên cứu lâm sàng can thiệp ở tất cả các bệnh nhân thuộc đối tượng nghiên cứu tại khoa HSTC BV Bach Mai từ 01/09/2020 đến 31/7/2021

- Quy trình theo dõi nồng độ thuốc amikacin trong máu: Các $B N$ được dùng liều đầu amikacin $30 \mathrm{mg} / \mathrm{kg} \mathrm{ABW}$, truyền thuốc trong 60 phút. (Nồng độ mục tiêu: C Ceak là $45-60 \mathrm{mg} / \mathrm{L}$, Cpeak/MIC: 8-10, Ctrough $<2 \mathrm{mg} / \mathrm{L}$ )

$\checkmark$ Lây máu mẫu 1 sau kết thúc truyền 30 phút đo $C_{\text {peak. }}$.

$$
\checkmark \quad \text { Lây máu mẫu } 2 \text { với BN có lọc máu đo }
$$

$C_{\text {trough }}$ trước 30 phút truyền liều tiếp. Lãy máu mẫu 2 đo $C_{\text {mid }}$ với bệnh nhân không lọc máu, thời gian lấy sau kết thúc truyền $4-32$ giờ tùy độ thanh thải creatinine của bệnh nhân (bảng dưới). Hiệu chỉnh khoảng liều thuốc dựa trên

$$
C_{\text {trough }} \mathrm{C}_{\text {trough }}=\mathrm{C}_{\text {mid }} \cdot \mathrm{e}^{-\mathrm{k}_{\mathrm{e}}\left(\tau-\mathrm{t}-\mathrm{t}_{2}\right)}
$$

(Trong đó: $\mathrm{Ke}$ : hằng số thải trừ; $\mathrm{C}_{\text {peak, }} \mathrm{C}_{\text {mid: }}$ 
kết quả định lượng tương ứng tại thời điểm

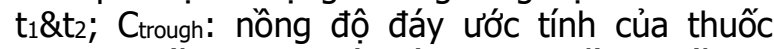
trong huyết tương; $\mathrm{t}$ là thời gian truyền thuốc; $\tau$ : khoảng cách đưa liêu)

\begin{tabular}{|c|c|}
\hline GFR (mI/phút) & Thời điếm lấy $\mathbf{C}_{\text {mid }}$ (giờ) \\
\hline$<20$ & $29-35$ \\
\hline $20-40$ & $22-26$ \\
\hline $40-80$ & $11-13$ \\
\hline $80-130$ & $5-7$ \\
\hline$>130$ & $3-5$ \\
\hline
\end{tabular}

\subsubsection{Chỉ tiêu nghiên cứu}

- Đặc điểm chung của đối tượng nghiên cứu: tuổi, giới, cân nặng, chiêu cao, BMI, mức độ nặng theo thang điểm APACHE II, SOFA lúc vào, điểm bệnh lý mắc kèm Charlson, MIC của K.pneumoniae với amikacin

- Hiệu quả lâm sàng

- Đáp ứng hoàn toàn: Các triệu chứng lâm sàng cải thiện, hết sốt $\&$ PCT giảm $\geq 80 \%$ (với PCT ban đầu $>5 \mathrm{ng} / \mathrm{mL}$ ) hoặc $\leq 0,5 \mu \mathrm{g} / \mathrm{L}$ (với PCT ban đầu $\leq 5 \mathrm{ng} / \mathrm{mL}$ )

- Đáp ứng một phần: Các triệu chứng lâm sàng cải thiện, sốt giảm \& PCT giảm

- Không đáp ứng: Triệu chứng lâm sàng không thay đổi hoặc nặng lên hoặc tử vong, sốt không cải thiện hoặc sốt cao hơn, PCT không giảm

- Tỷ lê xuất hiện tổn thương thận: dựa theo tiêu chuẩn RIFLE. Tổn thương thận được định nghĩa là tăng nồng độ creatinin huyết thanh trên 1,5 lần hoặc mức lọc cầu thận (GFR) giảm trên $25 \%$ so với giá trị tại thời điểm trước khi bắt đầu dùng thuốc, duy trì ít nhất trong 24 giờ và xảy ra sau ít nhất 2 ngày dùng amikacin. Tính $\mathrm{CrCl}$ theo công thức Cockcroft- Gault.

\subsubsection{Phân tích số liệu và xử lý số liệu}

Các số liệu được phân tích theo phương pháp thống kê y học

\subsection{4. Đạo đức trong nghiên cứu}

- Nghiên cứu nhằm mục đích điều trị và chăm sóc sức khỏe

- Các thông tin thu thập được từ BN chỉ được dùng cho mục đích nghiên cứu

\section{KẾT QUẢ NGHIÊN CứU}

3.1. Đặc điểm của bệnh nhân nghiên cứu. Nghiển cứu thực hiện trên 42 bệnh nhân có tuổi trung bình là $56,1 \pm 19,0$. Nam giới chiếm $76,2 \%$.

Bảng 1. Đặc điểm chung của bệnh nhân nghiên cứu

\begin{tabular}{|c|c|}
\hline Tiêu chí nghiên cứu & Trung bình \pm Độ lệch \\
\hline Cân nặng $(\mathrm{kg})$ & $58,9 \pm 10,6$ \\
\hline BMI $\left(\mathrm{kg} / \mathrm{m}^{2}\right)$ & $22,3 \pm 3,1$ \\
\hline Hct $(\%)$ & $29,8 \pm 7,1$ \\
\hline
\end{tabular}

\begin{tabular}{|c|c|c|}
\hline Alb $(\mathrm{g} / \mathrm{L})$ & \multicolumn{2}{|c|}{$27,9 \pm 5,4$} \\
\hline 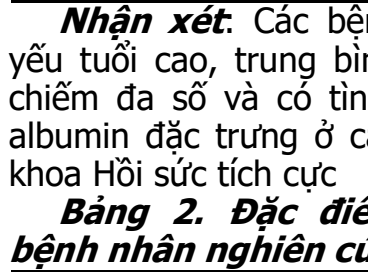 & nhân nc & $\begin{array}{l}\text { iên cứu chủ } \\
5,1 \text {, nam giới } \\
\text { u máu, giảm } \\
\text { n điêu trị tại }\end{array}$ \\
\hline Tiêu chí nghiên cứu & Trung vi & Tứ phân vị \\
\hline SOFA vào khoa & 8 & {$[4-11]$} \\
\hline APACHE II & 16 & [11-19] \\
\hline Chalson & 1 & {$[0-2]$} \\
\hline
\end{tabular}

Nhận xét: Các bệnh nhân nghiên cứu có điểm SOFA vào khoa cao, điểm APACHE II cao, mắc các bệnh lý mạn tính kèm theo, dự báo tình trạng nặng và nguy cơ tử vong caao.

\begin{tabular}{|c|c|c|}
\hline Tiêu chí nghiên cứu & Số lượng & Tỉ lệ \% \\
\hline Thở máy & 36 & 85,7 \\
\hline Sốc nhiểm khuẩn (SNK) & 15 & 35,7 \\
\hline Viêm phổi & 35 & 83,3 \\
\hline
\end{tabular}

Nhận xét. BN nghiên cứu chủ yếu là viêm phối $(83,3 \%)$, đa số cần thở máy $(85,7 \%)$. Tuy nhiên tỉ lệ sốc nhiễm khuẩn tương đối thấp $(35,7 \%)$

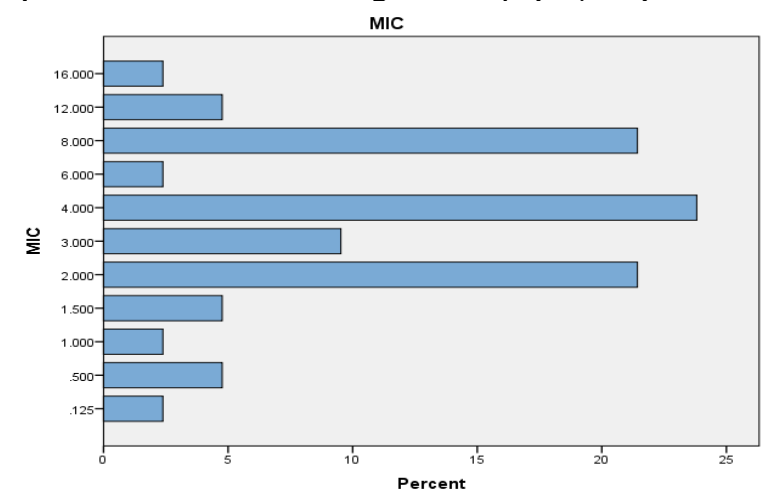

Biểu đồ 1. Phân bố giá trị nồng độ ức chế tối thiếu (MIC) cúa K. pneumoniae với kháng sinh amikacin

Nhân xét. Phần lớn MIC của K.pneumoniae với Amikacin là 4, tập trung ở khoảng 2-8. Tỉ lệ MIC $\leq 8$ là $92,9 \%$

3.2. Đánh giá kết quả đáp ứng lâm sàng

Bảng 4. Kết quả đáp ứng lâm sàng của bệnh nhân nghiên cứu

\begin{tabular}{|l|c|c|c|}
\hline & $\begin{array}{c}\text { Tỉ lệ̂ đáp } \\
\text { ứng } \\
\text { hoàn } \\
\text { toàn(\%) }\end{array}$ & $\begin{array}{c}\text { Tỉ lệ đáp } \\
\text { ứng một } \\
\text { phần(\%) }\end{array}$ & $\begin{array}{c}\text { Tỉ lệ } \\
\text { không } \\
\text { đáp ứng } \\
(\%)\end{array}$ \\
\hline Ngày 3 $(\mathrm{N}=42)$ & 11,9 & 64,3 & 23,8 \\
\hline Ngày 5 $(\mathrm{N}=42)$ & 31,0 & 50,0 & 19,0 \\
\hline Ngày 7(N=42) & 50,0 & 35,7 & 14,3 \\
\hline
\end{tabular}




\begin{tabular}{|c|c|c|c|}
\hline $\begin{array}{c}\text { Chung của điều } \\
\text { trị }(\mathrm{N}=42)\end{array}$ & 57,1 & 28,6 & 14,3 \\
\hline $\mathrm{P}(5-3)$ & $\mathbf{0 , 0 1 1}$ & & \\
\hline $\mathrm{P}(7-5)$ & $\mathbf{0 , 0 0 7}$ & & \\
\hline
\end{tabular}

Nhận xét. Tỉ lệ đáp ứng LS hoàn toàn chung của điểu trị là $57,1 \%$. Tỉ lệ BN đáp ứng lâm sàng hoàn toàn ngày thứ 5 có tăng so với ngày thứ 3 , ngày thứ 7 có tăng so với ngày thứ 5 với độ tin cậy $95 \%(p<0,05)$

Bảng 5. Các yêu tô ảnh hưởng đên kêt quả đáp ứng lâm sàng

\begin{tabular}{|c|c|c|c|c|}
\hline Tiêu chí nghiên cứu & $\begin{array}{l}\text { Đáp ứng } \\
\text { LS hoàn toàn } \\
(\mathrm{N}=24)\end{array}$ & $\begin{array}{l}\text { Khống đáp ứng } \\
\text { LS hoàn toàn } \\
(\mathrm{N}=18)\end{array}$ & $\mathbf{P}$ & $\begin{array}{c}\text { OR } \\
(95 \% \mathrm{CI})\end{array}$ \\
\hline Tuối (năm), trung bình \pm độ lệch & $57,3 \pm 18,0$ & $54,5 \pm 20,6$ & 0,648 & \\
\hline Giới tính nam, n (\%) & $18(75,0)$ & $14(77,8)$ & 1,000 & $0,857(0,2-3,6)$ \\
\hline Cân nặng $(\mathrm{kg})$, trung bình \pm độ lệch & $58,1 \pm 11,8$ & $60,0 \pm 9,0$ & 0,563 & \\
\hline BMI $\left(\mathrm{kg} / \mathrm{m}^{2}\right)$, trung bình \pm độ lệch & $22,0 \pm 3,4$ & $22,6 \pm 2,8$ & 0,519 & \\
\hline Hct (\%), trung bình \pm độ lệch & $31,7 \pm 8,4$ & $27,3 \pm 4,0$ & 0,033 & \\
\hline Alb $(\mathrm{g} / \mathrm{L})$, trung vi (tứ phân vi) & $28,5[25,9-32,5]$ & $26,8[24,8-27,7]$ & 0,058 & \\
\hline SOFA vào, trung vị (tứ phân vị) & $5[3-9,8]$ & $10[7,8-12]$ & 0,007 & \\
\hline APACHE II, trung bình \pm độ lệch & $14,0 \pm 4,3$ & $19,3 \pm 7,5$ & 0,012 & \\
\hline Chalson, trung vị (tứ phân vị) & $1[0-2]$ & $1[0-2]$ & 0,689 & \\
\hline $\begin{array}{c}\text { SOFA bắt đầu điều trị } \\
\text { trung bình } \pm \text { độ lệch }\end{array}$ & $6,3 \pm 3,4$ & $9,3 \pm 3,4$ & 0,009 & \\
\hline MIC (mg/L), trung vị (tứ phân vị) & $4[2-8]$ & $4[2-8]$ & 0,969 & \\
\hline Cpeak/MIC, trung vi(tứ phân vi) & $23,3[11,0-37,6]$ & $23,2[11,6-41,6]$ & 0,899 & \\
\hline PCT (ng/mL), trung vị (tứ phân vị) & $5,1[1,5-70,2]$ & $23,1[3,0-94,7]$ & 0,211 & \\
\hline $\begin{array}{l}\mathrm{PaO} / \mathrm{FiO} 2(\text { ngày 0) (BN viêm phối) } \\
\text { trung bình } \pm \text { độ lệch }\end{array}$ & $233,5 \pm 70,3$ & $213,0 \pm 64,9$ & 0,386 & \\
\hline BN có SNK, n (\%) & $6(25)$ & $9(50)$ & 0,094 & $0,333(0,1-1,2)$ \\
\hline BN có thở máy, n (\%) & $18(75)$ & $18(100)$ & 0,029 & $2,000(1,4-2,8)$ \\
\hline
\end{tabular}

Nhân xét: Hai nhóm có sư khác biêt về SOFA vào khoa, APACHE II, SOFA bắt đầu điều trị, Hct bắt đầu điều trị, tỉ lệ thở máy $(\mathrm{OR}=2, \mathrm{CI} 95 \%)$ có ý nghĩa thống kê $(p<0,05)$. Hai nhóm không có sự khác biệt về $C_{\text {peak }} / M I C, M I C(p>0,05)$.

3.4. Mô tả độc tính trên thận. Có $22 \mathrm{BN}$ thỏa mãn điều kiên nghiện cứu độc tính trên thận: $1 \mathrm{BN}$ có $C_{\text {trough }} \geq 2 \mathrm{mg} / \mathrm{L}\left(C_{\text {trough }}=2,09\right)$ và không có tổn thương thận. Trong $21 \mathrm{BN}$ còn lại có $8 \mathrm{BN}$ xuất hiện tổn thương thận cấp, chiếm $38.1 \%$ và thời gian xuất hiên là $6,1 \pm 3,6$ ngày

Bảng 6. Mức độ tổn thương thận khi $C_{\text {trough }}<2 \mathrm{mg} / \mathrm{L}$

\begin{tabular}{|c|c|c|}
\hline $\begin{array}{c}\text { Mức độ tốn thương } \\
\text { thận cấp }\end{array}$ & Số lượng & Tỉ lệ \% \\
\hline Nguy cơ' - R & 7 & $87,5 \%$ \\
\hline Tốn thương - I & 1 & $12,5 \%$ \\
\hline Suy - F & 0 & $0 \%$ \\
\hline
\end{tabular}

Nhận xét: Chủ yếu tốn thương mức $\mathrm{R}$ chiếm $87,5 \%$, không có $B N$ nào ở mức $F$ và không có $\mathrm{BN}$ nào phải lọc máu vì suy thận.

\section{BÀN LUẬN}

4.1. Đăc điểm chung của đối tượng nghiên cứu. Nghiên cứu trên 42 bệnh nhân, tuổi trung bình cao, chủ yếu nam giới, điểm
APACHE II và điểm SOFA cao, chủ yếu viêm phổi và thở máy tương tự như đặc điểm của các bệnh nhân nhiểm khuẩn do K.pneumoniae của các nghiên cứu Nguyễn Thị Tuyến $(2018)^{2}$, Trần Nhật Minh (2019) ${ }^{1}$, Kontopidou (2014) ${ }^{3}$, Vardakas (2015) ${ }^{5}$

4.2. Đánh giá kết quả đáp ứng lâm sàng. Tỉ lệ $\mathrm{BN}$ đáp ứng lâm sàng hoàn toàn chung của đợt điều trị là $57,1 \%$. Tỉ lệ này thấp hơn so với nghiên cứu Trần Nhật Minh (2019)2: 68,5\%, Nguyễn Thị Tuyến (2017)²: 69\%. So sánh về tiêu chuẩn và thời điểm đánh giá đáp ứng lâm sàng nhận thấy: Nghiên cứu của chúng tôi đánh giá đáp ứng lâm sàng dùng thêm các tiêu chuẩn về PCT và chia ra 3 mức độ đáp ứng (đáp ứng hoàn toàn, đáp ứng một phần, không đáp ứng). Tỉ lệ có đáp ứng lâm sàng (hoàn toàn và một phân) $85,7 \%$, cao hơn các nghiên cứu trên. Tỉ iệ không đáp ứng lâm sàng là $14.3 \%$ thấp hơn so với nghiên cứu Kontopidou $(2014)^{3}$ : 45,2\%. Điều này có thể do nghiên cứu của chúng tôi là điều trị đích, lấy các BN có K.pneumoniae nhạy cảm với amikacin, MIC phần lớn $\leq 8$, tî lệ đạt $C_{\text {peak }}$ MIC $\geq 8$ chiếm $88,1 \%$.

Tỉ lệ BN đáp ứng hoàn toàn ngày thứ 5 tăng so với ngày thứ 3 , ngày thứ 7 tăng so với ngày 
thứ 5 có ý nghĩa thống kê $(p<0,05)$. Điều này một phần phù hợp với hướng dẫn thời gian điều trị kháng sinh ở bệnh nhân nhiễm khuẩn huyết và viêm phổi (IDSA).

4.3. Mô tả độc tính trên thận. Nghiên cứu độc tính trên thận có $22 \mathrm{BN}$ thỏa mãn điều kiện: 1 BN có $C_{\text {trough }} \geq 2 \mathrm{mg} / \mathrm{L}\left(C_{\text {trough }}=2,09\right)$ và không có tổn thương thận, 21 BN còn lại có $38,1 \%$ xuất hiện tổn thương thận, chủ yếu tổn thương mức R. Kết quả tổn thương thận thấp hơn so với nghiên cứu Oliveira (2009) ${ }^{4}$ trên 360 BN ICU sử dụng Aminoglycosid $58 \%$ BN xuất hiện tổn thương thận, nghiên cứu này không thực hiện TDM và hiệu chỉnh liều dựa vào mức lọc cầu thận.

Thời gian xuất hiện tổn thương thận $6,1 \pm 3,6$ ngày tương tự nghiển cứu của Oliveira $(2009)^{4}$ $6,7 \pm 3,1$ ngày.

\section{KẾT LUẬN}

Tỉ lệ đáp ứng lâm sàng hoàn toàn khi điều trị viêm phổi, nhiễm khuẩn huyết do K.pneumoniae sử dụng amikacin liều $30 \mathrm{mg} / \mathrm{kg}$ ABW là $57,1 \%$. Bệnh nhân có điểm APACHE II cao, SOFA lúc vào khoa cao, SOFA lúc bắt đầu điều trị cao và bệnh nhân thở máy có đáp ứng lâm sàng kém hơn. Tỉ lệ tổn thương thận cấp ở các bệnh nhân nghiên cứu là $38,1 \%$.

\section{TÀI LIÊU THAM KHẢO}

1. Nguyễn Thị Tuyến, Phân tích thực trạng sử dụng kháng sinh carbapenem tại Bệnh viện Bạch Mai, Luận văn Thạc sỹ Dược học, Trường Đại học Dược Hà Nội, Hà Nô̂i, 2017.

2. Trân Nhật Minh Phân tích đặc điểm lâm sàng, vi sinh và phác đồ điều trị nhiếm khuẩn do Klebsiella pneumoniae tai khoa Hồi sức tích cực Bênh viên Bạch Mai, Luận văn tốt nghiệp Dược sĩ, trường Đại học Dược Hà Nội, Hà Nội, 2019.

3. Kontopidou F., Giamarellou H., et al., "Infections caused by carbapenem resistant Klebsiella pneumoniae among patients in intensive care units in Greece: a multi-centre study on clinical outcome and therapeutic options", Clinical Microbiology and Infection, 20(2), 2014 pp. 0117-0123.

4. Oliveira JF, Silva CA, Barbieri CD, Oliveira GM, Zanetta DM, Burdmann EA: Prevalence and risk factors for aminoglycoside nephrotoxicity in intensive care units. Antimicrob Agents Chemother 2009, 53:2887-2891.

5. Vardakas K. Z., Matthaiou D. K., et al, "Characteristics, risk factors and outcomes of carbapenem-resistant Klebsiella pneumoniae infections in the intensive care unit", J Infect, 70(6), 2015 pp. 592-9

\section{ĐÁNH GIÁ KẾT QUẢ ÁP DỰNG GÓI ĐIỀU TRI NHIỄM KHUẨN VÀ SỐC NHIỂM KHUẨN TRONG GIỜ ĐẦU TAI KHOA HỒI SỨC TÍCH CỰC, BÊ̂NH VIÊ̂N BẠCH MAI}

\section{TÓM TẮT.}

Mục tiêu: Đánh giá việc áp dụng gói điều trị nhiễm khuẩn và sốc nhiểm khuẩn trong giở đầu tại khoa Hồi sức tích cực, bệnh viện Bạch Mai. Đối tượng và phương pháp nghiên cứu: Nghiên cứu hồi cứu được tiến hành trên 96 bệnh nhân nhiếm khuẩn hoặc sốc nhiễm khuẩn tại khoa Hồi sức tích cực, bệnh viện Bạch Mai từ tháng 3/2021 tới tháng 10/2021. Việc áp dựng gói 1 giờ được chia làm 2 mức độ: tuân thủ và không tuân thủ. Kết quả điều trị khi áp dụng gói 1 giờ được đánh giá dựa vào kết cục lâm sàng, thơoi gian thở máy, thời gian dừng vận mạch, số ngày nằm viện và nằm tại khoa Hồi sức tích cực. Kết quả: Trong 96 bệnh nhẩn tham gia nghiên cứu, tỷ lệ nam giới là $54 \%$ và nữ giới là $46 \%$. Độ tuối trung bình là $60,0 \pm 17.3$ tuổi. Bệnh

\footnotetext{
*Trường Đại học Y Hà Nội

Chịu trách nhiệm chính: Đào Xuân Phương

Email: phuongdx110@gmail.com

Ngày nhận bài: 10.9.2021

Ngày phản biện khoa học: 3.11.2021

Ngày duyệt bài: 12.11.2021
}

\section{Đào Xuân Phương*, Bùi Thị Hương Giang*}

nhân nhiễm khuẩn là $33 \%$ và sốc nhiễm khuẩn chiếm $67 \%$ nhóm nghiên cứu, trong đó cao nhất là viêm phổi $(33,3 \%)$, nhiềm khuẩn tiêu hóa $(27,0 \%)$. Tỷ lệ tuân thủ là $57,3 \%$ và không tuân thủ là $42,7 \%$, trong đó tuân thủ dùng vận mạch cao nhất $(100 \%)$, thấp nhất là tuân thủ kháng sinh giờ đầu $66,7 \%$. Tỷ lệ tứ vong hoặc bênh nặng tiên lượng nặng xin về ở nhím tuân thủ thấp hơn có ý nghĩa thống kê so với nhóm không tuân thủ $(20,0 \%$ so với $43,9 \%, p<0,05)$. Thời gian thở máy ở nhóm tuân thủ ngắn hơn so với nhóm không tuân thủ $(5,0$ ngày so với 9,5 ngày, $p<0,05)$. Các tiêu chí về số ngày nằm viện, sô ngày nằm tại khoa hồi sức tích cực, thời gian dùng vận mạch ngắn hơn không có ý nghî̉a thống kê ở nhóm tuân thủ so với nhóm không tuân thủ $(p>0,05)$, Kết luận: Nghiên cứu bước đậu cho thây tuân thủ áp dụng gói 1 giờ theo hướng dẫn của Surviving Sepsis Campaign 2018 cải thiện kết cực điêuu trị của bệnh nhân nhiếm khuẩn hoặc sốc nhiếm khuẩn. Tuy nhiên, tỷ lệ tuân thủ còn thấp, cần có các chương trình tập huấn cho nhân viên y tế tại khoa Hồi sức tích cực.

Tư khóa: sốc nhiễm khuẩn, tuân thủ gói điều trị sốc nhiểm khuẩn 1 giờ. 